\section{The vertical position during labor: pain and satisfaction}

\section{Posição vertical durante o trabalho de parto: dor e satisfação}

\section{Abstract}

Objectives: to evaluate the vertical position adopted by nulliparous women during labor in terms of pain and satisfaction with the position.

Methods: the study was based on a secondary efficacy analysis of data from 107 nulliparous women enrolled in a randomized controlled trial in which the vertical position adopted during the dilation phase of labor was evaluated. The analysis involved comparing the median percentages of the duration for which women remained in the vertical position for each of the variables studied. The Kruskal-Wallis and Mann-Whitney tests were used to determine the differences between the groups. Statistical significance was set at $p<0.05$.

Results: at $4 \mathrm{~cm}$ of dilation, the women with a pain score $<5$ remained longer in the vertical position during labor compared to those with a score $>7$ $(p=0.02)$. At 4 and $6 \mathrm{~cm}$ of dilation, the women who reported greater satisfaction remained more than $50 \%$ of the time in the vertical position ( $p=0.02$ and $p=0.03$, respectively).

Conclusions: the vertical position helped relieve labor pain and increased comfort and patient satisfaction.

Key words Vertical position, Labor pain, Patient satisfaction, Humanizing delivery
Maria Amelia Miquelutti 1

Jose Guilherme Cecatti 2

Sirlei Siani Morais 3

María Yolanda Makuch 4

1-3 Department of Obstetrics and Gynecology. School of Medical Sciences. Universidade Estadual de Campinas. Campinas, SP, Brazil

4 Research Center for Reproductive Health of Campinas (CEMICAMP). Caixa postal 6181. CEP: 13.084-971. Campinas, SP, Brazil. E-mail: mmakuch@cemicamp.org.br

\section{Resumo}

Objetivos: avaliar a posição vertical, adotada por mulheres nuliparas durante o trabalho de parto, em relação à dor e satisfação com a posição.

Métodos: abordagem analítica distinta, complementar e de eficácia de 107 nulíparas, secundária aos dados de um ensaio controlado randomizado, que avaliou a posição vertical em nuliparas durante a fase de dilatação do trabalho de parto. A análise foi realizada pela comparação das porcentagens medianas do tempo de permanência na posição vertical para cada categoria das variáveis estudadas. Para testar as diferenças entre as variáveis foram utilizados os testes de Kruskal-Wallis e de MannWhitney. A significância foi estabelecida em $p<0.05$.

Resultados: aos $4 \mathrm{~cm}$ de dilatação, as mulheres que apresentaram escore de dor $<5$ permaneceram maior tempo do trabalho de parto na posição vertical quando comparadas às que tiveram escore $>7$ ( $p=0.02)$. As mulheres mais satisfeitas, aos 4 e $6 \mathrm{~cm}$ de dilatação, permaneceram mais de $50 \%$ do tempo na posição vertical ( $p=0.02$ e $p=0.03$, respectivamente).

Conclusões: a posição vertical auxiliou no alivio da dor, melhorou o conforto e satisfação das parturientes.

Palavras-chave Posição vertical, Dor do parto, Satisfação do paciente, Parto humanizado 


\section{Introduction}

Factors that contribute to maternal and fetal wellbeing are becoming an increasingly common requirement both for maternity hospitals committed to the humanization of childbirth and for women themselves. Non-pharmacological and non-invasive interventions to relieve pain and ensure the comfort of women during labor should be a primary concern and it is the responsibility of healthcare workers to provide guidance on practices based on scientific evidence in order to guarantee the safety of both mother and fetus. ${ }^{1}$

Among the numerous practices available, the vertical position during labor has received special attention, as it is a simple, inexpensive intervention that allows for a wide variety of positions. Although various positions adopted during labor and delivery have been studied over the past 40 years, controversy still surrounds the results regarding obstetric variables. ${ }^{2}$ Moreover, interest in the evaluation of the positions adopted during labor with respect to pain relief and comfort for women have yet to be fully clarified and there is thus as yet no consensus with regard to the optimal position to be adopted. Women in labor, when they are able to move around freely, have been reported to find and adopt various comfortable positions and to change position frequently. 2,3

With regard to obstetric variables, it is difficult to say whether there is any direct relationship between induced labor, duration of labor, incidence of cesarean section and the use of analgesics and the adoption of the vertical position during labor. 4 As for the effect of the vertical position on the well-being of the fetus and newborn, no reference can been found to any deleterious effect, such as fetal distress or low Apgar scores, associated with the adoption of the vertical position by the mother during labor. 2-17

So far as the humanization of childbirth is concerned, there is an urgent need to identify evidence-based practices that contribute towards both the well-being of the mother and the fetus. The aim of this study was, therefore, to evaluate the influence of the vertical position adopted by nulliparous women during labor, in terms of pain and satisfaction with the position adopted.

\section{Methods}

This was a secondary analysis with an analytical assessment of efficacy applied to the data resulting from a previously published randomized and controlled trial that evaluated the effect of the vertical position in nulliparous pregnant women during the dilation phase of labor in terms of pain and satisfaction of the women in labor and obstetric outcome. The study was carried out at the Department of Obstetrics and Gynecology of the School of Medical Sciences, at Universidade Estadual de Campinas (UNICAMP), Campinas, São Paulo, Brazil. The protocol was approved by the Institutional Review Board and the women enrolled signed an informed consent form prior to admission.

The study group was composed of 54 women who received guidance and were actively encouraged to adopt the vertical position. The control group comprised 53 women who were not given these instructions. Intention to treat analysis showed that, despite the instructions, women in both groups adopted both the vertical and horizontal positions at different points during labor and for different periods of time. 2 This contamination may have occurred due to women's observation of each other and as a result of the policy adopted by the maternity hospital in which the study was conducted of allowing the laboring women to adopt different positions.

The data from 107 low-risk pregnant nulliparous women, aged between 16 and 40 years, in labor at gestational age $\geq 37$ and $\leq 42$ weeks, with initial cervical dilation $\geq 3 \mathrm{~cm}$ and $\leq 5 \mathrm{~cm}$, with a single fetus in cephalic presentation and with strong vitality, were included in the present analysis. The socio-demographic and obstetric variables were analyzed according to the median percentage of the labor time that the women remained in the vertical position.

The time that the woman remained in the vertical and horizontal positions during labor was calculated based on self-reporting by the woman up to the moment when she received analgesics. Pain was evaluated in the interval between contractions using a 10-point visual analogue scale (VAS) in which 0 represented the absence of pain and 10 unbearable pain. 18 To evaluate satisfaction with the position adopted, a VAS was used in which a sequence of five faces with different expressions was provided according to which the women were able to indicate their degree of satisfaction in relation to the position they were in at that time as: very unsatisfied, unsatisfied, indifferent, satisfied or very satisfied. 19

The pain and the satisfaction scales were presented to the patients at three different points during labor: at approximately $4 \mathrm{~cm}, 6 \mathrm{~cm}$ and $8 \mathrm{~cm}$ of dilation, if the woman had not yet received analgesics by that time. For the analysis of satisfaction, the categories "very unsatisfied" and "unsatisfied", 
and "satisfied" and "very satisfied" were grouped as "unsatisfied" and "satisfied", respectively. The remaining procedures during labor, delivery and in the immediate puerperium were performed in accordance with the routine practices of the institution.

The analysis was carried out by comparing the median percentages of the time the women remained in the vertical position according to each category of the variables studied. The Mann-Whitney test was used to determine the differences between variables with up to two categories, while the Kruskal-Wallis test was used for variables with three or more categories. Significance was set at $p<0.05$.

\section{Results}

No statistically significant differences were found in terms of the median percentage of time women remained in the vertical position in relation to sociodemographic and obstetric characteristics on enrolment in the study, including age, marital status, level of schooling, obstetric history, the presence of a companion during labor, prenatal education, and use of uterotonics or type of delivery (Table 1).

The evaluation of pain according to the position adopted at $4 \mathrm{~cm}$ of dilation showed that the women who had a pain score $<5$ remained in the vertical position for around $41 \%$ of the duration of labor, whereas those who had a pain score $>7$ remained in this position for around $21 \%$ of labor-time ( $p=0.02$; Table 2). On the other hand, no significant differences were found at $6 \mathrm{~cm}$ of dilation. With respect to satisfaction with the position adopted, at 4 and 6 $\mathrm{cm}$ of dilation the women who were satisfied were found to have remained in the vertical position for more than $50 \%$ of the labor time $(p=0.02$ and

Table 1

\begin{tabular}{|c|c|c|c|}
\hline Characteristics & $\mathbf{N}$ & Median (\%) & $p$-value \\
\hline \multicolumn{4}{|l|}{ Age (years) } \\
\hline$\leq 20$ & 52 & 42.4 & 0.22 \\
\hline$\geq 21$ & 55 & 47.8 & \\
\hline Marital status & & & 0.39 \\
\hline With partner & 84 & 43.7 & \\
\hline Without partner & 23 & 37.5 & \\
\hline Level of education (years of schooling) & & & 0.27 \\
\hline$\leq 8$ & 52 & 41.7 & \\
\hline $9-12$ & 45 & 43.2 & \\
\hline$>12$ & 10 & 54.2 & \\
\hline Abortion & & & 0.10 \\
\hline No & 92 & 41.7 & \\
\hline Yes & 15 & 55.6 & \\
\hline Prenatal education & & & 0.69 \\
\hline Yes & 27 & 37.5 & \\
\hline No & 80 & 44.3 & \\
\hline Companion present & & & 0.79 \\
\hline Yes & 73 & 43.2 & \\
\hline No & 34 & 47.3 & \\
\hline Use of uterotonics & & & 0.63 \\
\hline Yes & 49 & 44.7 & \\
\hline No & 58 & 43.3 & \\
\hline Type of delivery & & & 0.51 \\
\hline Normal delivery & 67 & 41.7 & \\
\hline Cesarean section & 40 & 48.7 & \\
\hline
\end{tabular}


$p=0.03$, respectively; Table 2 ). The women who reported that they were unsatisfied with the position adopted remained in the vertical position for a median of $30 \%$ of the length of labor. Insufficient data were available for $8 \mathrm{~cm}$ of dilation, as by this time the majority of participants had already received analgesics.

Table 2

Percentage of time spent in the vertical position according to satisfaction with the position and pain.

\begin{tabular}{lccc}
\hline Characteristics & N & Median (\%) & p-value \\
\hline Satisfaction at $4 \mathrm{~cm}$ & & & 0.02 \\
$\quad$ Unsatisfied & 35 & 25.0 & \\
$\quad$ Indifferent & 40 & 42.6 & \\
$\quad$ Satisfied & 32 & 52.8 & 0.02 \\
Pain at $4 \mathrm{~cm}$ & & & \\
$\leq 4$ & 40 & 40.8 & \\
$5-7$ & 47 & 50.0 & 0.03 \\
$\geq 8$ & 20 & 21.5 & \\
Satisfaction at $6 \mathrm{~cm}$ & & & \\
Unsatisfied & 33 & 37.5 & 0.15 \\
Indifferent & 16 & 45.8 & \\
Satisfied & 21 & 55.6 & \\
Pain at $6 \mathrm{~cm}$ & & & \\
$\leq 4$ & 8 & 33.8 & \\
5 - 7 & 22 & 50.0 & \\
$\geq 8$ & 41 & 43.5 & \\
\hline
\end{tabular}

\section{Discussion}

The findings of this study suggest a reduction in reported pain during labor with the adoption of a vertical position. These results are similar to those reported by other investigators. ${ }^{13,20-22}$ A study that evaluated women's motives for using techniques to aid them during labor reported that, among the women who adopted the vertical position, the majority did so in response to pain and found relief in these positions. ${ }^{23}$ This finding may explain the fact that women in the present study who did not receive specific instructions with regard to the vertical position did in fact adopt the vertical position at various points during labor.

Our study also showed that women who remained in the vertical position for longer periods of time reported greater satisfaction and this accords with the results of two other studies 20,14 in which the preference of women in labor for the vertical position was observed. The fact that the vertical position allows for numerous variations, along with the progressive approach adopted at the maternity hospital where the study was carried out, gives women the freedom to find positions that will relieve pain and increase comfort. However, for cultural reasons, women often remain in the horizontal position during labor 24 and many do not have access to information on the vertical position or on alternative positions that could be adopted during labor during prenatal care or even during labor. When specifically instructed or encouraged to adopt the vertical position, women usually want to identify variations and spend most of the time in the vertical position when compared to those who did not receive guidance. ${ }^{1}$

According to Spiby et al., ${ }^{23}$ women in labor try to find different positions as a way of relieving anxiety and pain and consequently increasing comfort. Anatomically, the greater comfort provided by the vertical position may be explained by the change in the diameter of the pelvis compared to horizontal positions. Using X-ray pelvimetry, Russel 25 showed that when the woman is seated, the diameter of the pelvis is greater in comparison to the dorsal decubitus position.

This led us to reflect on the physiological, albeit unconscious, need for the woman to try to find posi- 
tions that facilitate the rotation and descent of the fetus, in view of the fact that such positions were widely adopted in the $17^{\text {th }}$ century, when there were no studies to demonstrate these changes, and were only discontinued for reason of medical convenience, initially during the second stage alone and later throughout the duration of labor. Simkin ${ }^{26}$ has defended the opinion that rhythmic movements during labor may modify the dimensions of the pelvis and facilitate rotation and descent of the fetus. These movements have also been widely used since antiquity.

According to Green and Baston, 27 the perception of internal control on the part of women in labor is related to the intensity of pain and, consequently, to satisfaction. The more intense the pain during labor, the lesser the feeling of control reported by women. The ability to find comfortable positions is directly related to the perception of external control and control of the contractions, thereby increasing satisfaction and well-being. Another study reported a similar observation, showing that personal satisfaction during labor was associated with internal control of pain, control of panic and of positions. 28 Although such analysis was not carried out in this study, the data reported here lead us to wonder whether more time spent in the vertical position during labor may be related to a heightened perception of control on the part of the women, resulting in less pain and greater satisfaction.

Some remarks should be made on the reason for using a complementary efficacy analysis to deal with data resulting from a randomized, controlled trial. This was done in view of the real possibility of a positive effect of the vertical position adopted by women during labor on maternal well being and on labor that is not clearly apparent in the randomized studies, because adherence and contamination are presented as confounding factors with regard to the effect of this intervention. It is obvious that in a randomized, controlled study, a laboring woman allocated to a horizontal position group cannot be prevented from adopting a vertical position at any time during labor if she wishes to do so. The opposite is also true in the case of women who were initially allocated to the vertical position group during labor. It would be neither ethical nor humane to prevent them from assuming the horizontal position for any length of time if they so desire.

In conclusion, the vertical position is a non-pharmacological practice that helps relieve pain and improves women's comfort during labor. Simple guidance from healthcare workers regarding the various vertical positions that may be adopted during labor may help women feel comfortable and minimize pain during this phase. This practice is in accordance with the directives established for the humanization of childbirth. ${ }^{1}$

\section{Acknowledgments}

Financial support was provided by FAEPEX/UNICAMP (Grant No. 24306) and CAPES. The authors are grateful to all the women that participated voluntarily in this study, to the Physical Therapy Department of the Women's Hospital, particularly to physiotherapists Neville de Oliveira Ferreira, Renata Guimaraes Vidigal, Maria Carolina Lessa and Camila Schneider Ganunny for their help during this study.

\section{References}

1. Brasil. Ministério da Saúde. Delivery, abortion and postpartum: humanized care to woman. Brasília, DF; 2001.

2. Miquelutti MA, Cecatti JG, Makuch MY. Upright position during the first stage of labor: a randomized controlled trial. Acta Obstet Gynecol Scand. 2007; 86: 553-8.

3. Carlson JM, Diehl JA, Sachtleben-Murray M, McRae M, Friedman EA. Maternal position during parturition in normal labor. Obstet Gynecol. 1986; 68: 443-7.

4. Souza JP, Miquelutti MA, Cecatti JG, Makuch MY. Maternal position during the first stage of labor: a systematic review. Reprod Health. 2006; 3: 10.

5. Liu YC. Effect of an upright position during labor. Am J Nurs. 1974; 74: 2202-5.

6. Flynn AM, Kelly J, Hollins G, Lynch PF. Ambulation in labour. Br Med J. 1978; 2: 591-3.
7. Diaz AG, Schwarcz R, Fescina R, Caldeyro-Barcia R. Vertical position during the first stage of the course of labor and neonatal outcome. Eur J Obstet Gynecol Reprod Biol. 1980; 11: 1-7.

8. Stewart P, Calder AA. Posture in labor: patients' choice and its effect on performance. Br J Obstet Gynaecol. 1984; 91: 1091-5.

9. Andrews CM, Chrzanowski M. Maternal position, labor and comfort. Appl Nurs Res. 1990; 3: 7-13.

10. McManus TJ, Calder AA. Upright posture and the efficiency of labor. Lancet. 1978; 1: 72-4.

11. Williams RM, Thom MH, Studd JW. A study of the benefits and acceptability of ambulation in spontaneous labour. Br J Obstet Gynaecol. 1980; 87: 122-6. 
12. Bloom SL, McIntire DD, Kelly MA, Beimer HL, Burpo RH, Garcia MA, Leveno KJ. Lack of effect of walking on labor and delivery. N Engl J Med. 1998; 339: 76-9.

13. Hemminki E, Saarikoski S. Ambulation and delayed amniotomy in the first stage of labor. Eur J Obstet Gynecol Reprod Biol. 1983; 15: 129-39.

14. Hemminki E, Lenck M, Saarikoski S, Henriksson L. Ambulation versus oxytocin in protracted labour: a pilot study. Eur J Obstet Gynecol Reprod Biol. 1985; 20: 199208.

15. Albers LL, Anderson D, Cragin L, Daniels SM, Hunter C, Sedler KD, Teaf D. The relationship of ambulation in labor to operative delivery. J Nurse Midwifery. 1997; 42: 4-8.

16. Read JA, Miller FC, Paul RH. Randomized trial of ambulation versus oxytocin for labor enhancement: a preliminary report. Am J Obstet Gynecol. 1981; 139: 669-72.

17. Roberts JE, Mendez-Bauer C, Blackwell J, Carpenter ME, Marchese T. Effects of lateral recumbency and sitting on the first stage of labor. J Reprod Med. 1984; 29: 477-81.

18. Huskisson EC. Measurement of pain. Lancet. 1974; 2 : 1127-31.

19. Sampieri RH, Collado CF, Lucio PB. Metodologìa de la Investigacion. Second edition. Mexico: Mc Graw-Hill; 1998: 255-92.

20. Méndez-Bauer C, Arroyo J, Garcia Ramos C, Menéndez A, Lavilla M, Izquierdo F, Villa Elízaga I, Zamarriego J. Effects of standing position on spontaneous uterine contractility and other aspects of labor. J Perinat Med. 1975; 3: 89100 .

Recebido em 14 de julho de 2008

Versão final apresentada em 13 de março de 2009

Aprovado em 14 de agosto de 2009
21. Melzack R, Bélanger E, Lacroix R. Labor pain: effect of maternal position on front and back pain. J Pain Symptom Manage. 1991; 6: 476-80.

22. Adachi K, Shimada M, Usui A. The relationship between the parturient's positions and perceptions of labor pain intensity. Nurs Res. 2003; 52: 47-51.

23. Spiby H, Slade P, Escott D, Henderson B, Fraser RB. Selected coping strategies in labor: an investigation of women's experiences. Birth. 2003; 30: 189-94.

24. Dundes L. The evolution of maternal birthing position. Am J Public Health. 1987; 77: 636-41.

25. Russell J. Moulding of the pelvic outlet. J Obstet Gynaecol Br Commonw. 1969; 76: 817-20.

26. Simkin P. Maternal positions and pelves revisited. Birth. 2003; 30: 130-2.

27. Green JM, Baston HA. Feeling in control during labor: concepts, correlates and consequences. Birth. 2003; 30: 235-47.

28. Slade P, MacPherson SA, Hume A, Maresh M. Expectations, experiences and satisfaction with labour. $\mathrm{Br} \mathrm{J}$ Clin Psychol. 1993; 32: 469-83. 